\title{
Hubungan Tingkat Pendidikan Berbasis Islam Anggota Karang Taruna Dengan Kepedulian Sosial
}

\author{
Moch Hawin $^{1}$ \\ ${ }^{1}$ Progam Studi Pendidikan Agama Islam Fakultas Agama Islam (FAI), Universitas Hasyim Asy’Ari
}

\begin{tabular}{|c|c|}
\hline Article Info & ABSTRACT \\
\hline Article history: & Islam Islamic religious education is a conscious and planned effort in \\
\hline Received Apr 17, 2019 & $\begin{array}{l}\text { preparing students to get to know, and understand, appreciate, to believe in the } \\
\text { history of Islam, accompanied by demands to respect adherents of Islam in }\end{array}$ \\
\hline Accepted Aug 3, 2019 & relation to harmony between religious communities to realize national unity \\
\hline & $\begin{array}{l}\text { and unity. Caring is a basic value and attitude to pay attention and act } \\
\text { proactively to the conditions or circumstances around us. This study aims to }\end{array}$ \\
\hline Keywords: & $\begin{array}{l}\text { determine and analyze the relationship between the level of Islamic-based } \\
\text { education with the social care of members of the village of Karang Taruna. }\end{array}$ \\
\hline Islamic education & The population in this study were all members of the Kebontemu village of \\
\hline Adolescents & Karang Taruna Karang, while the study sample was taken by simple random \\
\hline Social & $\begin{array}{l}\text { sampling method with a total of } 30 \text { members of Karang Taruna. The results } \\
\text { of the research hypothesis and test on the relationship found that there is a } \\
\text { positive relationship between the level of Islamic-based education on social } \\
\text { care that exists in the members of the Karang Taruna Kebontemu village }\end{array}$ \\
\hline
\end{tabular}

This is an open access article under the CC BY-SA license.

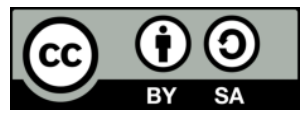

\section{Corresponding Author:}

Moch Hawin,

Progam Studi Pendidikan Agama Islam Fakultas Agama Islam (FAI)

Universitas Hasyim Asy’Ari

Email: Victor.first95@gmail.com

\section{PENDAHULUAN}

Pendidikan agama islam adalah usaha sadar dan tereencana dalam menyiapkan murid untuk mengenal, dan memahami, menghayati, hingga mengimanai sejarah islam, di barengi dengan tuntutan untuk menghormati penganut agama islam dalam hubungannya dengan kerukunan antar umat beragamaa hingga terwujud kesatuan dan persatuan bangsa. Fungsi sekolah sebagai pembentuk nilai dalam diri anak sekarang ini banyak menghadapi tantangan. Umumnya di kota berkembang sekarang ini sangat berasa adanya banyak lingkungan lain yang dapat di pilih remaja selain sekolahnya, yaitu pasar swalayan, pusat pembelanjaan dan warung di tepi jalan. Apa lagi sering kali motivasi belajar murid memang menurun akibat adanya berbagai hal di sekolah. Salah satunya memfaktor yang di anggap menurunkan motivasi belajar adalah materi pelajaran itu sendiri dan pendidik yang menyampaikan pelajaran itu.

\section{METODE}

Dalam penelitian terdapat beberapa dua gaya penelitian yaitu penelitian kuantitatif, yang datanya langsung di ambil dari narasumber dan menggunakan data-data kepustakaan yang ada kaitannya. Dan yang kedua metode penelitian kuantitatif yang bersifat angka dan data yang di olah menggunakan metode statistika, untuk kali ini peniliti menggunakan metode penelitian kuantitatif.

Penelitian kuantitatif dapat dilihat dari hubungan variabel obyek yang valid lebih bersifat dari sebabakibat. Sehingga penelitian ini ada dua variabel independen dan satu dependen. Dalam eksplorasi ini peneliti berusaha meneliti dan mencari ada tidaknya hubungan antara tingkat pendidikan agama anggota karang taruna dengan kepedulian di desa kebontemu. Sehingga eksplorasi ini menggunakan penelitian Ex Post Facto dan untuk jenis penelitian yang di gunakan adalah jenis korelasional. 
Observasi dengan metode pendekatan kuantitatiif akan menekankan pada analisisnya terhadap data angka-angka yang diolah dengan model statistika. Pada dasarnya pendekatan kuantitatif dilakukan pada penelitian inverensial (dalam rangka pengujian hipotesis) dan menyadarkan kesimpulan hasilnya pada suatu probabilitas kesalahan penolakan hipotesis nihil. Dengan metode kuantitatif akan diperoleh signifikasi perbedaan kelompok atau signifikansi hubungan antar variabel yang diteliti.

Hipotesis itu sendiri menggambarkan tentang hubungan antara dua variabel atau lebih untuk mengetahui apakah kedua variabel tersebut berasosiasi ataukah tidak dengan variabel yang lainnya dan untuk mengetahui antara variabel tersebut ada pengaruhnya apa tidak. Dalam penelitian ini menggunakan jenis penelitian eksperimen. Eksperimen adalah penelitian yang ada perlakuan (treatment), dalam hal ini penelitian ini adalah metode penelitian yang digunakan untuk mencari pengaruh perlakuan tertentu terhadap yang lain dalam kondisi yang terkendalikan (Sugiyono, 2016: 72).

Subyek dan Objek Penelitian

Subyek penelitian adalah seseorang atau sesuatu yang mengenainya ingin diperoleh keterangan. Dalam sebuah penelitian subyek memiliki peran yang sangat strategis, karena pada subyek penelitian itulah data tentang variabel penelitian yang akan diamati (Suharsimi Arikunto, 2010: 201).

Dalam hal ini yang menjadi subyek penelitian adalah seluruh anggota karang taruna desa kebontemu yang berjomlah 40 orang, sedangkan objek peneloitian dari penelityian ini adalah kepedulian sosial yang ada di desa kebontemu.

Instrumen Penelitian

Karena pada prinsipnya meneliti adalah melakukan pengukuran, maka harus ada alat ukur yang baik. Alat ukur dalam penelitian disebut instrumen penelitian. Adapun instrumen sendiri adalah alat untuk mengukur informasi atau melakukan pengukuran. Instrumen penelitian merupakan alat bantu bagi peneliti dalam mengumpulkan data (Suharsimi Arikunto, 2010: 134).

Instrumen penelitian adalah suatu alat yang digunakan mengukur fenomena alam maupun sosial yang diamati (Sugiyono, 2016: 102). Instrumen penelitian adalah alat atau fasilitas yang digunakan oleh peneliti dalam mengumpulkan data agar pekerjaannya lebih mudah dan hasilnya lebih baik, dalam arti lebih cermat, lengkap, dan sistematis sehingga lebih mudah diolah (Suharsimi Arikunto, 2010: 203).

a. Jenis dan Skala Data

Skala pengukuran merupakan kesepakatan yang digunakan sebagai acuan untuk mengukur panjang pendeknya interval yang ada dalam alat ukur, sehingga alat ukur tersebut bila digunakan dalam pengukuran akan menghasilkan data kuantitatif. (Sugiyono, 2016: 133).

Adapun skala yang digunakan dalam penelitian ini adalah skala 5S yang menggunakan lima tingkatan. Subjek diminta untuk menyatakan kesetujuan atau ketidaksetujuan terhadap isi pernyataan. Setiap item akan diberikan empat pilihan jawaban, yakni Sangat Setuju (SS), Setuju (S), Ragu-ragu (R), Tidak Setuju (TS), Sangat Tidak Setuju (STS).

Pada skor skala $5 S$ ini, terdapat dua pernyataan yaitu:

Favourable, yakni pernyataan yang bersifat positif atau mendukung terhadap objek.

Unfavourable, yakni pernyataan yang berisi hal-hal yang negatif atau kontra terhadap objek yang akan diteliti (Azwar, 2007: 98).

Untuk pernyataan favourable penilaian bergerak mulai dari angka 4 sampai 1 . Sedangkan unfavourable peniliaian bergerak mulai dari angka 1 sampai 4.

Jabaran Variabel

Susunan dalam penelitian dikembangkan melalui jabaran variabel dari instrumen penelitian ini adalah:

TABLE I. $\quad 3.2$

\begin{tabular}{|c|c|c|c|c|}
\hline Variabel & Indikator & Sumber & Metode & No Soal \\
\hline $\begin{array}{l}\text { Tingkat } \\
\text { Pendidikan }\end{array}$ & $\begin{array}{l}\text { Madrasah ibtidaiyah } \\
\text { Madrasah Tsanawiyah } \\
\text { Madrasah aliyah } \\
\text { Sarjana (Universitas Islam) }\end{array}$ & Anggota karang taruna & Angket & $\begin{array}{l}1,2,3 \\
4,5,6 \\
7,8 \\
9,10\end{array}$ \\
\hline Kepedulian Sosial & $\begin{array}{l}\text { Gotong royong (Zubaidu, } 2006: 33 \text { ) } \\
\text { Empati } \\
\text { Demokrasi (Sakho Muhammad, } 2006: 268 \text { ) }\end{array}$ & Anggota karang taruna & Angket & $\begin{array}{l}1,2,3 \\
4,5,6 \\
7,8,9,10\end{array}$ \\
\hline
\end{tabular}

Dalam instrumen penelitian disini, terdapat 20 soal. Skor tertinggi yang mungkin akan dicapai adalah $5 \mathrm{x}$ $20=100$, dan skor yang terendah yang mungkin dicapai adalah 1 × $20=20$, sehingga akan diperoleh kriteria sebagai berikut: 


\begin{tabular}{|c|c|c|}
\hline $\mathrm{NO}$ & Kategori & Kelas Interval \\
\hline 1. & Sangat Baik & $81-100$ \\
\hline 2. & Baik & $61-80$ \\
\hline 3. & Cukup & $41-60$ \\
\hline 4. & Kurang Baik & $21-40$ \\
\hline 5. & Sangat Kurang & $0-20$ \\
\hline
\end{tabular}

Uji Validitas dan Realibilitas

Salah satu masalah utama dalam kegiatan penelitian adalah memperoleh data informasi yang akurat dan obyektif. Hal ini menjadi sangat penting artinya karena suatu penelitian hanya akan dapat dipercaya apabila didasarkan pada informasi yang juga dapat dipercaya. Melihat kondisi ini maka alat pengumpul data mempunya peran yang sangat penting, karena tingkat akurasi dan kecermatan hasil pengukuran tergantung pada validitas dan reliabilitas alat ukur. Alat pengumpul data harus memiliki kriteria reliabel dan valid agar kesimpulan penelitian tidak keliru dan tidak memberikan gambaran yang jauh berbeda dari keadaan yang sebenarnya.

Menurut Azwar validitas berasal dari kata validity yang mempunyai arti sejauh mana dan kecermatan suatu alat ukur dalam melaksanakan fungsi ukurnya. Atau dengan kata lain mampu tidaknya suatu alat ukur tersebut mencapai tujuan pengukurannya yang dikehendaki dengan tepat (Saifuddin Azwar, 2000: 173). Validitas adalah suatu konsep yang berkaitan dengan sejauhmana suatu alat ukur telah mengukur apa yang seharusnya diukur (Sugiyono, 2016: 110). Validitas lebih berupa derajat kedekatan kepada kebenaran dan bukan masalah sama sekali banar atau sekali salah. Validitas adalah suatu proses yang tak perah berakhir. Suatu cara pengukuran yang telah lama sekali diyakini akan validitasnya, suatu ketika ditemukan bukti-bukti baru akan kesalahan atau kekurangannya, sehingga dilakukan penyempurnaan atau perubahan prosedur dan alat ukur tersebut (Djunaidi Ghony, 2009: 195).

Dalam penelitian ini menggunakan uji validitas konstrak (Construct validity) untuk mengetahui instrumennya valid atau tidak (Sugiyono, 2016: 172). Dalam hal ini setelah instrumen dikonstruksikan tentang aspek-aspek yang akan diukur dengan berlandaskan teori tertentu. Adapun uji validitas statistik dapat dilakukan dengan menggunakan rumus person product moment, yaitu:

$$
r_{x y}=\frac{n \sum x_{i} y_{i}-\left(\sum x_{i}\right)\left(\sum y_{i}\right)}{\left.\sqrt{\left\{n \sum x_{i} 2-\left(\sum x_{i}\right)^{2}\right\}\left\{n \sum y_{i} 2-\left(\sum y_{i}\right)^{2}\right.}\right\}}
$$

Keterangan:

$$
r_{x y} \quad: \text { koefisien korelasi }
$$

$N \quad$ : banyaknya data keseluruhan

$\sum \mathrm{X}$ : jumlah skor $\mathrm{X}$

$\sum \mathrm{Y}$ : jumlah skor $\mathrm{Y}$

Kriteria pengujian adalah :

$$
\begin{array}{r}
r_{\text {hitung }} \geq r_{\text {tabel }} \rightarrow \text { valia } \\
r_{\text {hitung }} \leq r_{\text {tabel }} \rightarrow \text { tidakvalia }
\end{array}
$$

Pengujian ini dilakukan dengan cara mengkorelasikan antara skor item setiap butir pernyataan dengan skor total, koefisien korelasi yang dihasilkan kemudian dibandingkan dengan $\mathrm{r}_{\text {tabel }}$, bila dikorelasikan antara skor item dengan total skor kurang dari 0,30 (didapat dari perhitungan interpolasi dari tabel nilai r Product Moment). (Leli Siti Hadianti, 2008: 18) Maka item pertanyaan dalam instrumen tersebut dinyatakan tidak valid. Item instrumen dianggap valid jika lebih besar dari 0,3 dengan membandingkan dengan $\mathrm{r}$ tabel. Jika $r_{\text {hiung }} \geq r_{\text {tabel }}$ maka valid (Suharsimi Arikunto, 2013: 170).

Reliabilitas

Reliabilitas merupakan penerjamahan dari kata reliability yang berarti sejuah mana hasil suatu pengukuran dapat dipercaya (Saifuddin Azwar, 2005: 180) Reliabilitas adalah menunjuk pada tingkat keterdalaman sesuatu. Data yang reliabel adalah data yang dihasilkan dapat dipercaya dan diandalkan. Apabila datanya memang benar-benar sesuai dengan kenyataannya, maka berapa kali pun diambil, tetap akan sama (Suharsimi Arikunto, 2010: 10) Reabilitas merupakan ukuran suatu kestabilan dan konsistensi responden dalam menjawab hal yang berkaitan dengan konstruk-konstruk pertanyaan yang merupakan dimensi suatu variabel dan disusun dalam suatu bentuk kuisioner. (Bhuono Agung Nugroho, 2005: 72)

Tehnik Pengumpulan Data

Teknik pengumpulan data berdasarkan tekniknya, yaitu melalui obervasi, angket atau kuisioner dan dokumentasi. 
Observasi. Observasi sebagai teknik pengumpulan data mempunyai ciri yang spesifik. Sutrisno Hadi (1986) mengemukakan bahwa, observasi merupakan suatu proses yang komplek, suatu proses yang tersusun dari berbagai proses biologis dan psikologis. Dua diantara yaang terpenting adalah proses-proses pengamatan dan ingatan. Dari segi proses pelaksanaan pengumpulan data, observasi dapat dibedakan menjadi participant (observasi berperan serta) obsevation dan non participant observation, selanjutnya dari segi instrumentasi yang digunkan, maka observasi dapat dibedakan menjadi observasi terstruktur dan tidak struktur (Sugiyono, 2016: 145)

Angket Atau Kuisioner. Angket atau kuesioner adalah daftar pertanyaan yang diberikan kepada orang yang bersedia memberikan respon (responden) sesuai dengan permintaan pengguna. Tujuan penyebaran angket adalah mencari informasi yang lengkap mengenai suatu masalah dari responden tanpa merasa khawatir bila responden memberikan jawaban yang tidak sesuai dengan kenyataan dalam pengisian daftar pertanyaan. Disamping itu responden mengetahui informasi tertentu yang diminta (Margono, Cipta, tt: 158). Dokumentasi. Metode dokumentasi adalah metode dengan cara mencari data mengenai hal-hal yang berkaitan dengan variabel yang berupa catatan, transkip, buku, surat kabar, majalah, prasasti, notulen rapat, lengger, agenda.

\section{HASIL DAN PEMBAHASAN}

Bagi anggota karang tarunma sendiri diharapkan dapat meningkattkan kualitas mengajar serta mengembangkan potensi guru serta kreativitas guru dalam menumbuhkan motivasi belajar siswa, agar supaya dapat mencapai keberhasilan serta menunjang mutu pendidikan. Dan Perilaku sosial karang taruna akan lebih baik dan tidak akan menyimpang jika di dasari dengan pendidikan agama yang baik Sedangkan pendidikan agama sendiri Menampilkan perilaku sebagai khalifah di bumi, ikhlas dalam beribadah, hidup demokrasi, berkompetisi dalam kebaikan, menyantuni kaum Dhu'afa, menjaga kelestarian lingkungan hidup, bertoleransi, dan melakukan pengembangan Iptek merupakan perilaku yang harus ditimbulkan dari pembelajaran aspek atau mata peljaran Qur'an/Hadist.

\section{Macam-macam tingkatan pendidikan berbasis islam}

Tahun 1952, pemerintah menyempurnakan melalui Peraturan Menteri Agama Nomor 7/1952. Dalam peraturan ini jenjang (tingkat pendidikan agama formal) pendidikan madrasah meliputi : Tingkat Pertama

Madrasah sebagai salah satu lembaga pendidikan Islam di Indonesia dituntut untuk dapat ikut andil dalam usaha membangun SDM Indonesia yang berkualitas dan berguna bagi kehidupan. Jenjang pendidikan madrasah yang terdiri atas Madrasah Ibtida'iyah (MI), Madrasah Tsanawiyah (MTs), dan Madrasah Aliyah (MA), yang tidak terlepas dari tiga misi atau tujuan yang harus di jalankan, yaitu : Menanamkan keimanan kepada anak didik, Menumbuhkan semangat dan sikap untuk mengamalkan ajaran-ajaran dalam rangka pembangunan, Memupuk toleransi antara sesama pemeluk agama di indonesia dengan saling pahami misi luhur masing-masing agama, Kepedulian Sosial merupakan sikap kebaikan dan kedermawanan perlu di butuhkan, peka dengan perasaan orang, orang yang membutuhkan pertolongan siap dibantu, tidak pemah berbuat kasar, dan tidak menyakiti perasaan orang lain.

Nilai yang di setujui oleh kehidupan masyarakat,indonesia akan memunculkan sikap kesadaran kepedulian. Kognisi merupakan sikap yang menginfasi akan hak dan kewajiban, derajat dan peran serta dalam kehidupan kekerabatan. Kepedulian berarti sikap menghargai,menghormati, mengecamkan, mengindahkan atau menghiraukkan lingkungan sekitarnya.

\section{KESIMPULAN}

Hasil penelitian dapat dijadikan sebagai bahan studi agama lanjutan yang relevan dan kajian ke arah pengembangan belajar agama remaja untuk meningkatkan kepedulian sosial sesuai dengan norma-norma yang berlaku. Pembahasan pendidikan agama sangatlah penting untuk di tanamkan di usia remaja bahkan usia dini salah satunya supaya bisa menanamkan perilaku sosial yang baik bagi masyarakat sekitar.

\section{REFERENSI}

Arifah, Asma. 2013. Penanaman nilai-nilai kepedulian sosial melalui pembiasaan infaq di SMP Negeri 15 Yogyakarta: UIN Sunan Kalijaga Yogyakarta.

Arikunto, Suharsimi. 2010. Manajemen Penelitian. Jakarta: Rineka Cipta.

Azwar, 2007. Metode Penelitian. Yogjakarta: Pustaka Belajar.

Baharuddin, 2010. Pendidikan dan Psikologi perkembangan, Yogjakarta: arruz media.

Hadianti, Leli Siti. 2008. Pengaruh Pelaksanaan Tata Tertib Sekolah Terhadap Kedisiplinan Belajar Siswa (Penelitian Deskriftif Analisis di SDN Sukakarya II Kecamatan Samarang Kabupaten Garut), Jurnal 
Pendidikan Universitas Garut, Vol. 02; No. 01; hlm. 1-8, Margono, Metode Penelitian Pendidikan (Jakarta: PT. Rineka Cipta)

Muchlas Samani, 2013. “Konsep dan Model Pendidikan Karakter”. Bandung: PT. Remaja Rosdakarya. Muhammad, Sakho 2006. Ahsi. Ensiklopedia Al-Quran. Jakarta, Batara Offiset.

Mukhtaruddin, "pengaruh pendidikan agama terhadap perilaku keagamaan peserta didik sma swasta di kota yogyakarta", Analisa Volume XVIII, No. 01, (Januari - Juni 2011)

Nugroho, Bhuono Agung. 2005. Strategi Jitu Memilih Metode Statistik Penelitian dengan SPSS. Yogyakarta: CV. Andi Offset.

Saifuddin Azwar, 2005. Metode Penelitian . Yogyakarta: Pustaka Belajar.

Sarwono, Sarlito W 2015. psikologi remaja, (jakarta: PT raja grafindo,)

Sugiyono, 2016. Metode Penelitian Pendidikan Pendekatan Kualitatif, Kuantitatif, Dan R \& D. Bandung: Alfabeta.

Suharsimi Arikunto, 2010. Prosedur Penelitian Suatu Pendekatan Praktek. Jakarta: Rineka Cipta.

Zubaidu, 2006. Pendidikan Berbasis Masyarakat. Yogyakarta: Pustaka Belajar.

Zulkifli, L. 2009. Psikologi Perkembangan Remaja. Bandung: Rosdakarya. 